\title{
FROM SUSTAINABLE TO TRANSIENT COMPETITIVE ADVANTAGE
}

\author{
Tsvetana STOYANOVA, Miglena ANGELOVA \\ University of National and World Economy, Sofia, Bulgaria \\ tsvetana_stoyanova@unwe.bg; m.angelova.phd@gmail.com
}

\begin{abstract}
The concept of competitive advantage is central for the strategic management literature. The researchers' ideas in this field are broad and comprehensive - from an attempts to define and measure the advantage, through its sources, to the complex of conditions that presuppose its existence at all, and its preservation for a longer period. The activities to protect it in a highly dynamic environment are a great challenge. This makes the topic of the necessary and sufficient requirements that the sources of competitive advantage have to meet in order to ensure its sustainability. Studying the conditions needs the sustainability to be defined, and with respect to the requirements of dynamism coming from the outside environment. The purpose of this article is to study, systematize and summarize existing scientific opinions about the conditions that ensure the sustainability for the competitive advantage and to identify the reasons for moving to its flexibility. In order to achieve this objective, it is necessary to fulfil the following tasks: - to consider the prerequisites for sustainability and to derive a definition of "sustainable competitive advantage"; - to highlight the specific features of the transitional competitive advantages; - to indicate the implementation of the two concepts in business organizations.
\end{abstract}

Keywords: competitive advantage; sustainable advantage; transient advantage; Strategic Management

\section{Introduction}

Dynamic development of business environment with all players and stakeholders involved in it poses serious questions to the enterprises management. The main goal of the Strategic Management of each company now is to focus on the finding such a competitive advantage that allow company to secure market positions for the longest possible period. But one of the specific features of the market today is its unpredictability due to the complexity of factors such as: globalization, rapid development of high technologies, customers' behaviour, and competitions at different levels. However, business strive to reduce this uncertainty in the external environment by providing the company with a good market position due to the specific competitive advantage.

Increasing requirements of clients from one hand and rapid changing market conditions from the other hand demand company to be as flexible as never before. Management is forced to seek competitive advantage literally in any process, operation, product characteristic, clients' service etc.

We could claim that the real sustainable competitive advantage possess only few enterprises in a specific economy sectors. The rest of them have to implement flexible market policy in order to ensure some type of competitive advantage. This is the reason why researchers recently pay special attention to the transient advantage than sustainable advantage. 
2. Significance of the competitive advantage for the strategic management and market position of the company

2.1. Specific features of the sustainable competitive advantage

Sustainable competitive advantage is the subject and focus of numerous researches and authors. Therefore the scientific literature is rich in definitions and classification of this concept. In general, there are two main groups competitive advantages, based on the different factors internal and external for the organization. Jean-Jaques Lambin [3] claims that external factors for competitive advantages include: the level of the country's competitiveness, competitiveness of the organization itself, the capacity of the competitiveness among competitors, the capacity of the competitiveness among suppliers, the existence and competition between substitute products, the possibility of market expansion through new customers etc. On the other hand Lambin divides into six major groups internal factors for competitive advantages (Fig.1)

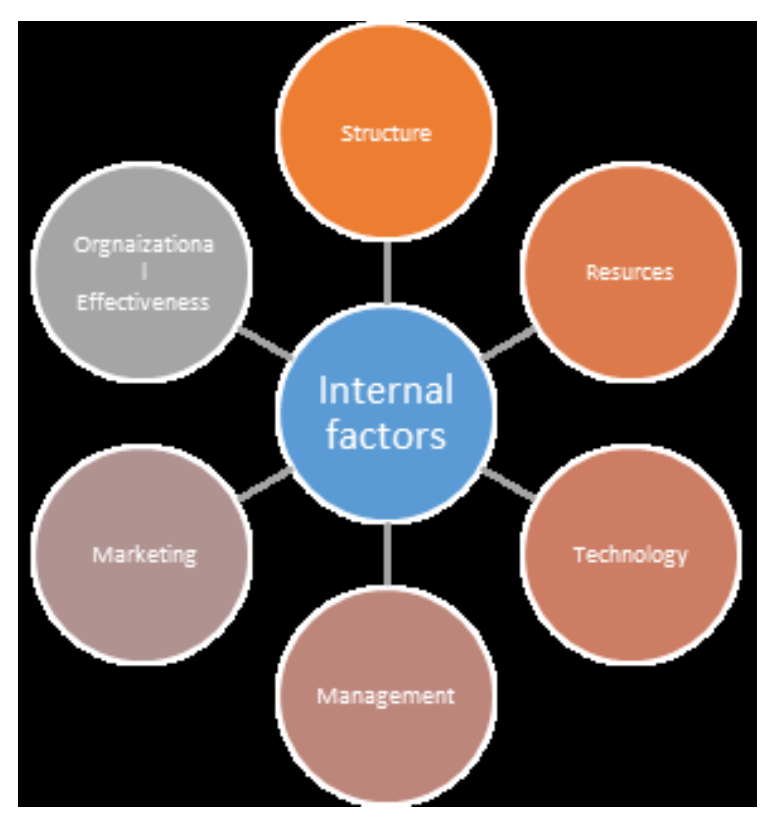

Figure 1: Internal factors for competitive advantages, based on the Lambin's concept

One of the world-renown scientists devoted his efforts to analyse competitiveness is
Michael Porter. In [7] he develops three generic competitive strategies:

- Cost Leadership Strategy - company relies on low costs, based on the optimization of expenditure for production and distribution;

- Differentiation Strategy - here the competitive advantage is based on the specification of a product or service that makes it unique on the market;

- Focus Strategy - the company's target are specific groups of customers that company knows best and is able to satisfy their needs.

The concept of finding (or creating), developing, implementing competitive advantage and turning it into sustainable is significant and comprehensive. Many researchers explore this problem from different perspectives, looking for interrelations, characteristics, analyzing in details different elements of the enterprise's system.

One of the greatest challenges for modern economic life is unpredictability and complexity of the environment due to the rapid change of high technologies and their influence and reflection on the different industries.

Regardless of different approaches to studying competition in general and competitive advantage in particular, all scientists share the idea that having the competitive advantage is of strategic importance for the present and future development of the company. However, for organizations that work in highly competitive industries, where the goods and services offered by companies are extremely close, finding a competitive advantage may be a difficult tasks with many risks and unknown future. This is the reason for thesis of many authors who claim that different concepts and policies such as corporate social responsibility or internal human resource development policy could be considered as an elements of the competitive advantage $[1,5,8,9]$. 
Nowadays competitive advantages can be reasonably find almost everywhere, including in the clients' behavior [Schrage, $10]$. But the major and most important question is how to turn this advantage into sustainable advantage - i.e. what are the main characteristics of the sustainable competitive advantage.

According Kunkoro and Suriani for instance, [2] in long term competitive advantage, companies acquire sustainable competitive advantage through their ability in developing a set of main competence so that they can service their targeted customers better than their competitors. They examine the relationship between product innovation and sustainable competitive advantage. One of their findings shows that the higher new product innovation, the higher sustainable competitive advantage. They prove that new product innovation really has an effect on sustainable competitive advantage of an organization.

Looking for a response of this question, fundamental for the companies and competitiveness in general, many scientists consider the sustainability as a part of the company's overall policy. They associate the meaning of sustainability with the idea of corporate reputation and image, clients' relationships and the role of intangible resources to achieve long-term development, good performance and market positions [4, 6].

\subsection{Specific features of the transitional competitive advantages}

As a result of globalization many of barriers and regulations that protect both enterprise and entire sectors have been dropped. Nowadays competition is not just internal (national, regional or local), but it involves companies from all over the world without taking into account their geographical and physical location. The raise of digitization creates instantaneous information flows making the conditions more transparent and as a result of this - the attractive opportunities - more visible to more market players and even turns the needed resources more accessible. All of these mentioned dynamics make it very difficult the challenge to secure competitive advantage for a long period.

The presumption of stability creates wrong reflects. Inertia and routine predetermine conditions for organizational stiffness. They interfere innovations and play as a burden for proactive planning the next strategic step. However, in the context of the knowledge economy, companies should be better and better in understanding their clients' needs and for what customers are willing to pay, in order to receive better results in accordance with new effects from existing assets.

Well known postulate that companies compete within its branch and once they achieve competitive advantage it will be sustainable for a long period, nowadays are less and less effective. Indeed there are examples of advantages that could be maintained over the time such as the usage of strong customer relationships, for specific industries such as aircraft construction, mining industry, food industry, where some companies manage to retain their advantage for some time. But this is not the situation in the majority of the economic sectors, nor for the main part of the present enterprises. Music, high technologies, travel, communication, consumer electronics, automotive business and even the education are faced with situations, where the competitive advantages are duplicated quickly, technological changes and customers are looking for new alternatives and this is the way that things progress. They are several indicators that may foretell the fact that the competitive advantage of the company fades, such as: the emergence of the new competitors from unexpected circumstances, companies from different industries that are beginning to show the rising interest in what the company is doing; collapse of the traditional barriers to 
entry into the industry; cheap substitutes goods for market products.

Today's competition can come from everywhere. This is not only the question of the cheap goods substitutes targeting insolvent clients and then gradually improved to swerve high class customers. Now whole products lines or the established logic of entire market could be destroyed almost for a night. Companies have to do things in a different way in order to compete effectively in this unstable and uncertain environment. Products` characteristics, new technologies as well as better offers are advantages that turn out to be less durable that we thought. Instead companies have to learn and use more ephemeral activities such as closer customer relationships and to create the ability to design irreplaceable experiences. They have to focus on creating capabilities and skills that are significant in the areas where they operate. Thus could be lead to their composure on the traditional mechanisms for protections and entry barriers, because the competition will move on the highly intangible and emotional factors.

The formula for building customer relationships based on experiences [12] connects audiences through authentic essence of the brand, through their participation in adequate, reliable and memorable encounters. In a world, full of demanding clients who are used to do with multiple channels to bind to each other, the business has no choice but to change. It has to adapt to the constantly added value to the client service and to encourage relationships based on the cooperation through innovations.

Innovations could be considered as a technique of transforming business from static to much more dynamic state. They result not only in the development of new business idea, new technologies approbation or in the creation of the new processes and systems. Today innovations are also needed in creation and implementation of these ideas and the way in which the corresponded infrastructures support their development.

According to popular definitions innovation of business model refers to creation or rebuilding of the business itself. If innovations are mainly associated with a new product or service, the innovation of business model leads to the formation of a totally different type of company that not only competes with the others market players on the base of added value of the offered products and services, but also coordinates its profit policy, resources and process in a way that increase the these added value, to conquer new market segments and to eliminate competitors.

Each organizations using innovations, passes through four stages while placing the clients in the centre of the business and on this perspective to secure the adaptive competitive advantage:

- Predictable business - focused on the traditional operations and one-way communication. When in the closer environment changes happen, these organizations find it difficult to comprehend the new opportunities and for this reason risks to lose their competitive market position and not to understand the significance with clients ' relationships.

- Social business - at this stage organization passes through the effective relationships with customers and begin to communicate effectively and interactively with them.

- Related business - at this stage organizations work actively to connect key stakeholders, people, processes. Employees are directly involved not only to each other, but also with customers.

- Adaptive business - at this stage organization is capable and flexible to transform and evolve under any circumstances so effectively that can predict opportunities and threats before they become reality. By placing the customer in the centre, the company has 
the ability to derive insights for short term and long term innovations and transformations.

Adaptive business opens doors between business units to promote cooperation within organization. The framework for sCRM and relationships allow operations, technologies and human resources to focus on the new customers' needs by creating new experiences. This is also related to the change in the organizational structure and working processes in order to integrate the new clients' requirements. (Fig.2)

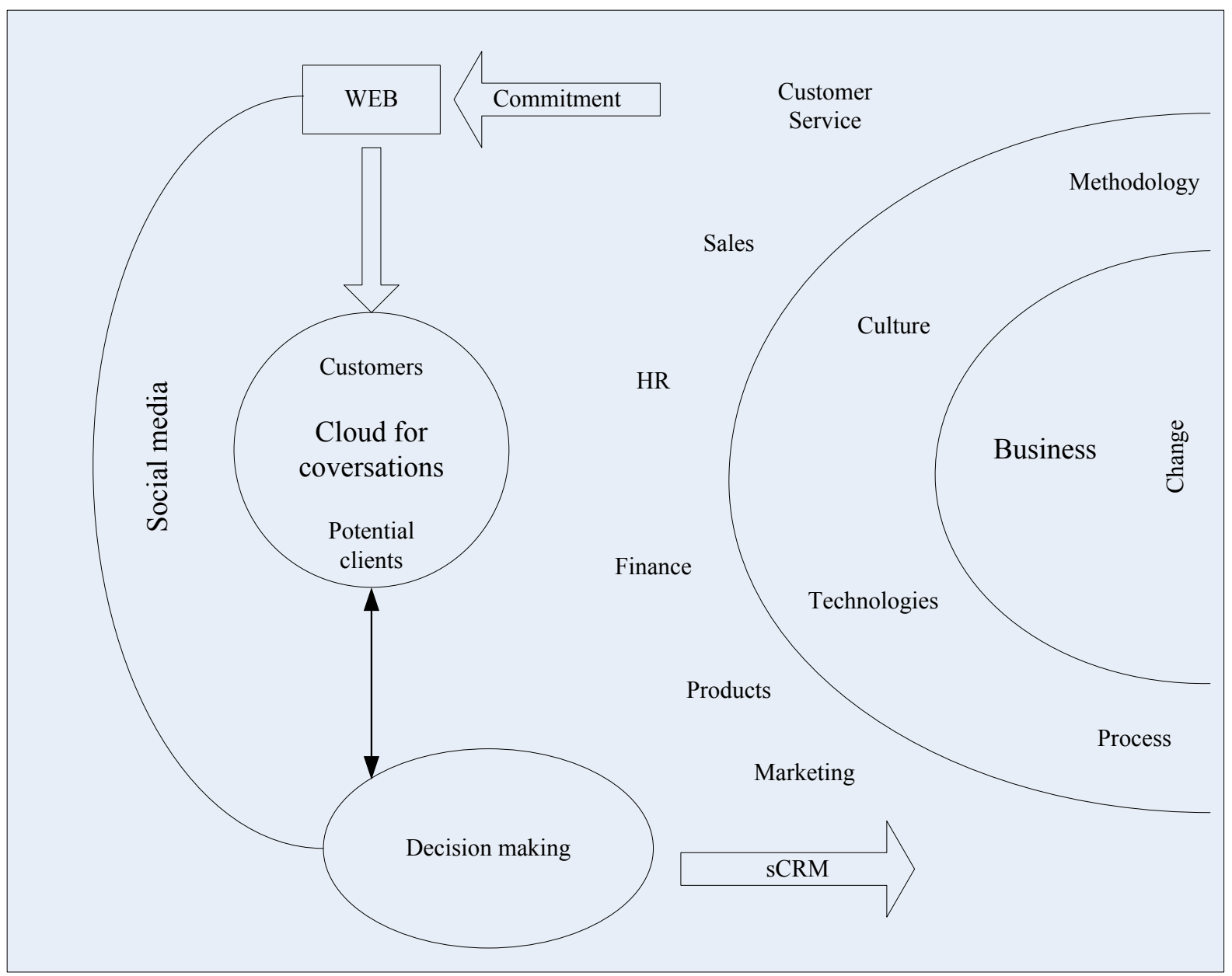

Figure 2: Framework for adaptive competitive advantage, based on the concept of Solis [11]

In a world full of demanding customers, business has no choice but to change. It has to adapt to the continuous adding value to the clients services and to promote relationships built on the base of cooperation. Change Management requires the support of the entire organization.

\section{Conclusions}

The concept of transitional corporate advantage reflects the dynamics, the unpredictability, the uncertainty of environment, based on the fast development of high-technologies, the customers ' behavior that compose the essence of the today's economy world. The only successful way out of the business organizations under these circumstances is to constantly manage change in their attempts to achieve sustainability. 


\section{References}

[1] Dyer, W., Team Building: Issue and Alternatives. Reading. MA. Addison-Wesley, 1997.

[2] Kuncoro, W., \&Suriani, W. O., Achieving sustainable competitive advantage through product innovation and market driving, Asia Pacific Management Review (2017), http://dx.doi.org/10.1016/j.apmrv.2017.07.006.

[3] Lambin, J-J., Shuiling, I., Market-Driven Management, Strategic and Operational Marketing, 3rd Edition, Palgrave Macmillan, London, United Kingdom, 2012.

[4] McMillan, G. \& Joshi, M., How Do Reputations Affect Corporate Performance? Sustainable Competitive Advantage and Firm Performance: The Role of Intangible Resources, Corporate Reputation Rev (1997), V.1, Issue 1, p. 81-85.

[5] Munilla, L. S. and M. P. Miles. The Corporate Social Responsibility Continuum as a Component of Stakeholder Theory. Business and Society Review. p. 371-387. 2005.

[6] Švárová, M., Vrchota, J., Influence of competitive advantage on formulation business strategy, Enterprise and the Competitive Environment 2014 conference, ECE 2014, 6-7 March 2014, Brno, Czech Republic, Procedia Economics and Finance 12 ( 2014 ) p. $687-694,2014$.

[7] Porter, M. E. The Competitive Advantage: Creating and Sustaining Superior Performance. NY: Free Press, 1998.

[8] Porter, M. E. and M. R. Kramer. The Competitive Advantage of Corporate Philanthropy. Harvard Business Review p. 56-68. 2002.

[9] Porter, M. E. and M. R. Kramer. The link between competitive advantage and corporate social responsibility. Harvard Business Review p. 78-92. 2006.

[10] Schrage, M., Your Customers'Behavior Is a Competitive Advantage, Harvard Business Review, January 2015.

[11] Солис, Брайън. Новият бизнес модел: Успехът в революиията на потребителите изисква промяна, Рой Комюникейшън, София, 2015, стр.328

[12] http://smallbusiness.chron.com/experiential-marketing-defined-as-23722.html 